\title{
Operação de transporte e tempo de descanso na incidência de carne PSE em suínos
}

\author{
Sivanilza T. Machado ${ }^{1}$, Rodrigo C. Santos ${ }^{2}$, Fabiana R. Caldara ${ }^{3}$, \\ Manoel C. Gonçalves ${ }^{4}$, Rodrigo A. Jordan ${ }^{5} \&$ João G. M. dos Reis ${ }^{6}$ \\ ${ }^{1}$ Doutoranda, UNIP, São Paulo, SP. E-mail: sivanilza.machado@strictoengprod.unip.br (Autora correspondente) \\ ${ }^{2}$ UFGS, Dourados, MS. E-mail: rodrigocouto@ufgd.edu.br \\ ${ }^{3}$ UFGD, Dourados, MS. E-mail: fabianacaldara@ufgd.edu.br \\ ${ }^{4}$ UFGD, Dourados, MS. E-mail: manoelgoncalves@ufgd.edu.br \\ ${ }^{5}$ UFGD, Dourados, MS. E-mail: rodrigojordan@ufgd.edu.br \\ ${ }^{6}$ UNIP, São Paulo, SP. E-mail: jgilbertomreis@unip.br
}

\section{Palavras-chave:}

PSE

manejo pré-abate ambiência

regressão logística

técnica stepwise

\begin{abstract}
R E S U M O
Este estudo foi conduzido com o objetivo de investigar a incidência de carne PSE (pale, soft and exudative) em suínos abatidos em um abatedouro comercial, localizado em Mato Grosso do Sul, no período de maio de 2009 a julho de 2010. A partir do banco de dados $(\mathrm{n}=854$ carcaças), aplicou-se a regressão logística múltipla com a finalidade de desenvolver um modelo para constatar a influência das variáveis selecionadas na probabilidade de risco de incidência de carne PSE. Desta forma, a variável dependente foi construída pela identificação de carne PSE em carcaças de suínos com valores de $\mathrm{pH}_{45}$ inferior ou igual a 5,8. Para obtenção do modelo com maior capacidade de predição foram aplicados o método de máxima verossimilhança para estimação de parâmetros e a técnica stepwise para seleção de variáveis explicativas. As variáveis selecionadas com maior poder de predição foram: temperatura de carcaça, tempo de embarque, velocidade média durante o transporte e o tempo de descanso médio dos animais nas baias. O modelo obtido apresentou capacidade de predição de $91,8 \%$.
\end{abstract}

\section{Key words:}

PSE

pre-slaughter management

environment

logistic regression

stepwise technique

\section{Transportation management and resting time on the occurrence of PSE meat in pigs}

\begin{abstract}
A B S T R A C T
The aim of this study was to investigate the occurrence of PSE (Pale, Soft and Exudative) meat in pigs slaughtered in a commercial slaughterhouse located in the Mato Grosso do Sul, from May 2009 to July 2010. Based on a database ( $\mathrm{n}=854$ carcasses), multiple logistic regression was applied for the purpose of developing a model to verify the effect of the selected variables on the probable risk of occurrence of PSE meat. Thus, the dependent variable was constructed through the identification of PSE meat in pig carcasses with $\mathrm{pH}_{45}$ values less than or equal to 5.8. In addition, the maximum likelihood method for estimation of parameters and the stepwise technique for selection of covariates were applied to obtain the model with the highest predictive ability. The variables selected with the greatest predictive capability were: carcass temperature, time of shipping, average speed during transport and the average resting time of the animals in the stalls. The obtained model presented predictive capability of $91.8 \%$.
\end{abstract}

\section{INTRODUÇÃo}

A duração do transporte de animais, em especial de suínos, pode ser extremamente estressante afetando suas condições físicas e psíquicas (Santos et al., 2013). O ambiente térmico, o tipo de veículo, a densidade, a movimentação, o embarque e o desembarque, o horário de coleta e o uso de equipamentos adequados, influenciam o bem-estar do animal durante a operação de manejo pré-abate (Mota-Rojas et al., 2012; Schwartzkopf-Genswein et al., 2012).

O transporte de animais deve ser muito bem planejado considerando-se as boas práticas de manejo animal, o bemestar e o conforto térmico, haja vista que a movimentação inadequada implica em sintomas como aumento dos batimentos cardíacos, ansiedade e medo, dentre outros (Delezie et al., 2007). As situações que geram o máximo estresse para o animal são os momentos do embarque e desembarque, devido à interação homem-animal e de mudança de ambiente (Silveira, 2010), consequentemente, gerando perdas para a cadeia suinícola.

Em seu estudo sobre o impacto econômico das perdas do transporte para o mercado baseado no abate de suínos (em kg), para a indústria estadunidense em 2006, Ritter et al. (2009) apresentaram índices médios de $0,22 \%$ (suínos mortos) e $0,44 \%$ (suínos inaptos) significando uma perda financeira direta por animal de US $\$ 105,03$ e US $\$ 17,18$, respectivamente e perdas financeiras indiretas de US $\$ 20,47$ por animal, para ambos os 
casos. O valor total estimado para a perda financeira direta no transporte foi US\$31.796.810,00 e indireta de US\$14.008.481,00, ou seja, um custo de aproximadamente 46 milhões de dólares para a indústria.

Em regiões de clima quente, como no Brasil, cuidados no transporte de animais têm sido discutidos por diversos autores, entre eles: Dalla-Costa et al. (2007), Silveira (2010), Santiago et al. (2012) e Santos et al. (2013). A zona de conforto térmico para suínos em terminação varia entre temperaturas de 12 a $18{ }^{\circ} \mathrm{C}$ e umidade relativa do ar entre 60 a $80 \%$, sendo mais recomendados 70\% (Leal \& Nääs, 1992). O ambiente térmico é avaliado em razão de índices de conforto térmico que consideram parâmetros ambientais de temperatura, umidade, vento e radiação, com peso de importância relativa para o animal (Saraiva et al., 2003; Baêta \& Souza, 2010). Assim, pode-se citar o índice de temperatura e umidade (ITU), índice de temperatura de globo e umidade (ITGU), a carga térmica radiante (CTR), representando a sensação térmica dos animais em relação ao ambiente (Sampaio et al., 2004).

O tempo de descanso no frigorífico tem sido utilizado como importante prática de manejo possibilitando a recuperação dos animais do estresse físico e emocional ocorrido no transporte (Santiago et al., 2012). Entretanto, diversos autores e especialistas divergem entre si quando tratam do período ótimo de descanso para os animais no frigorífico. Santiago et al. (2012) recomendam, em seus estudos, a aplicação do tempo de descanso entre 6 a 8 h; Ludtke et al. (2012), sugerem até $6 \mathrm{~h}$ de descanso. Venturini et al. (2007), defendem períodos maiores de descanso recomendando entre 16 a $24 \mathrm{~h}$. Segundo Silveira (2010), essas diferenças entre as recomendações de tempo de descanso no frigorífico ocorrem em virtude de não haver, ainda, um tempo mínimo de descanso após a viagem do animal, que concilie o bem-estar e os custos da empresa transportadora.

O descanso no frigorífico deve ser associado à logística: distância entre granja e abatedouro, condições de transporte, mistura de lotes e temperatura ambiente, além da intensidade do estresse a que os suínos foram submetidos durante o manejo pré-abate (Giespert et al., 2000).

A qualidade da carne suína depende de diversas atividades que estão ligadas aos fatores ante-mortem, em que o animal foi submetido antes do abate (Costa et al., 2002) e post-mortem, razão pela qual a indústria vem desenvolvendo tecnologia no transporte de animais a fim de reduzir as perdas oriundas das operações de manejo pré-abate e transporte. Carcaças que apresentam carne tipo PSE (pale, soft, exsudative - pálida, macia e exsudativa) se desenvolvem em virtude de glicólise anaeróbica post-mortem muito rápida reduzindo o $\mathrm{pH}$ e a conversão do glicogênio a lactato.

Objetivou-se, então, avaliar a influência do transporte e do tempo de descanso na qualidade da carne suína $(\mathrm{n}=854)$ num abatedouro comercial, no Estado de Mato Grosso do Sul, região de clima predominantemente quente e seco, por meio da técnica multivariada de regressão logística múltipla, para determinar as variáveis mais associadas à ocorrência de carne PSE.

\section{Material e Métodos}

Foram analisadas 854 carcaças provenientes de 16 lotes de suínos e de ambos os sexos (macho e fêmea) a partir do banco de dados de um abatedouro comercial situado no Estado de Mato Grosso do Sul, no período de maio de 2009 a julho de 2010.

Os dados meteorológicos referentes à data da avaliação no abatedouro foram obtidos da Estação meteorológica da UFGD, situada a $22^{\circ} 11^{\prime} 45^{\prime \prime}$ de latitude sul e $54^{\circ} 55^{\prime} 18^{\prime \prime}$ de longitude norte. Utilizando o valor médio diário de temperatura e umidade relativa do ar calcularam-se as temperaturas de bulbo seco (Tbs) e bulbo úmido (Tbu) do ar através do programa Psicrom ${ }^{\circledast}$ (Roriz, 2003) e posteriormente os Índices de Temperatura e Umidade (ITU) através da Eq. 1 (Roller \& Goldman, 1969).

$$
\mathrm{ITU}=0,45 \mathrm{Tbu}+1,35 \mathrm{Tbs}+32
$$

em que:

ITU - índice de temperatura e umidade

Tbu - temperatura de bulbo úmido, ${ }^{\circ} \mathrm{C}$

Tbs - temperatura de bulbo seco, ${ }^{\circ} \mathrm{C}$

Para o embarque dos suínos utilizou-se de rampas elevadiças até a carroceria do caminhão. O transporte dos animais foi realizado em caminhões (tipo truck, com 16 divisórias e carreta com 24 divisórias), equipados com carroceria em alumínio com dois pisos. A densidade de transporte obedeceu a faixa de 250 a $280 \mathrm{~kg}$ de peso vivo por $\mathrm{m}^{2}\left(0,35\right.$ a $\left.0,40 \mathrm{~m}^{2} 100 \mathrm{~kg}^{-1}\right)$.

As variáveis analisadas neste estudo foram: potencial hidrogeniônico após $45 \mathrm{~min}$ do abate $\left(\mathrm{pH}_{45}\right)$, temperatura da carcaça (TC), em ${ }^{\circ} \mathrm{C}$, Índice de Temperatura e Umidade (ITU), tempo de embarque (TE) em horas, tempo de viagem (TV) em horas, distância entre a granja e o frigorifico (DK) em km, velocidade média (VM) em $\mathrm{km} \mathrm{h}^{-1}$, tempo de descanso médio na baia do abatedouro (TD) em horas. Para determinação da velocidade média durante o transporte dos suínos considerouse a relação espaço (distância, em $\mathrm{km}$ ) pelo tempo de duração da viagem (em horas).

Visando à aplicação da estatística foi realizada, inicialmente, uma análise descritiva dos dados amostrais e posterior análise de regressão logística múltipla, por meio da opção stepwise

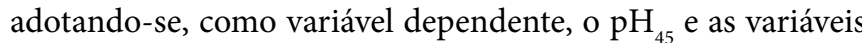
explicativas: TC, ITU, TE, TV, DK, VM e TD. A construção da variável de incidência de carne PSE ' $Y$ ' surgiu a partir do valor do $\mathrm{pH}_{45}$ da carcaça considerando-se $\mathrm{Y}=0$ para valores de $\mathrm{pH}>5,8$, caso a carcaça não apresentasse incidência de carne PSE e $\mathrm{Y}=1$ para valores de $\mathrm{pH} \leq 5,8$, se a carcaça apresentasse incidência de carne PSE (Santiago et al., 2012).

A análise de regressão logística múltipla é um modelo estatístico que objetiva descrever a relação entre uma variável dependente (resposta) e uma ou mais variáveis explicativas, no intuito de encontrar o mais apropriado, econômico e razoável modelo para apresentar tal relação, sendo distinguida da regressão linear pela variável resposta ser binária ou dicotômica (Hosmer et al., 2013). Além disso, possibilita obter a razão de chance (Odds Ratio), ou seja, a razão entre a probabilidade 
que um evento irá ocorrer sobre a probabilidade que o mesmo evento não irá ocorrer (Mendes \& Veja, 2011). Esta é uma propriedade importante da regressão logística pois permite calcular as chances de ocorrência do evento; no caso deste estudo permite calcular a probabilidade de ocorrência de carne PSE.

O modelo matemático da regressão logística múltipla adaptado de Hosmer et al. (2013) é representado pela seguinte Eq. 2:

$$
Y=\frac{e \beta 0+\sum_{j=1}^{p-1} \beta j X j}{1+e \beta 0+\sum_{j=1}^{p-1} \beta j X j}
$$

Sendo, assim, a variável dependente $\mathrm{Y}$ e as variáveis independentes X1, X2, ..., Xp-1. O objetivo é a construção de um modelo que relacione a variável Y com as variáveis X's, dispondo-se, para tanto, de n observações (Hosmer et al., 2013). No estudo esta é a principal razão pela escolha do modelo logístico pois serve para descrever uma probabilidade do evento "carne PSE em carcaças de suínos" ocorrer sendo que para realizar a predição foi adotado o ponto de corte $(\mathrm{pc}=0,1)$.

Para simplificar o modelo logístico pode-se representar por $\mathrm{P}(\mathrm{X})$, Eq. 3:

$$
P(X)=\frac{e+\sum_{j=1}^{p-1} \beta j X j}{1+e \beta 0+\sum_{j=1}^{p-1} \beta j X j}
$$

em que:

$\mathrm{Y}=\mathrm{P}(\mathrm{X})+\varepsilon$, sendo que $\varepsilon$ pode assumir um de dois possíveis valores:

Se $Y=1$, então $\varepsilon=1-P(X)$, com probabilidade $P(X)$

Se $\mathrm{Y}=0$, então $\varepsilon=-\mathrm{P}(\mathrm{X})$, com probabilidade $1-\mathrm{P}(\mathrm{X})$

O banco de dados (854 carcaças) foi dividido em três períodos de tempo de transporte, com números de amostras diferentes para cada período obtendo-se o Período $1(\leq 0,83 \mathrm{~h}$, $23 \%$ do total, equivalendo a $\mathrm{n}=195$ carcaças), o Período 2 (entre 0,84 a 1,66 h, $73 \%$ do total, representando a $n=623$ carcaças) e o Período 3 ( $\geq 1,67 \mathrm{~h}, 4,0 \%$ do total, equivalendo a $\mathrm{n}=36$ carcaças), para a análise da estatística descritiva no intuito de comparar os períodos de tempo de transporte.

A aplicação da regressão logística múltipla com a técnica de seleção de variáveis stepwise foi utilizada para amostra total (n $=854$ carcaças) sendo a escolha do modelo reduzido baseado no critério de informação Akaike (AIC).

A análise estatística foi realizada pelo programa computacional SAS Versão 9.00 (Shtatland et al., 2003).

\section{Resultados e Discussão}

A amostra dividida em três períodos de tempo de transporte possibilitou uma análise mais criteriosa dos dados e a incidência de carne PSE. De acordo com a Tabela 1, a incidência de carne PSE na amostra foi detectada no Período 1, em 16 carcaças (1,87\%); já no Período 2, em 44 (5,15\%) e no Período 3, em 9 carcaças $(1,05 \%)$. A somatória dos resultados dividiu a amostra total em dois grupos: 785 carcaças sem incidência e 69 com incidência de carne PSE (8,07\%).

Tabela 1. Frequência absoluta e relativa de carne PSE entre os três períodos de transporte

\begin{tabular}{ccccc}
\hline $\begin{array}{c}\text { Tempo de } \\
\text { transporte (h) }\end{array}$ & $\begin{array}{c}\text { Observação } \\
\text { (carcaça) }\end{array}$ & $\begin{array}{c}\text { Frequência } \\
\text { absoluta (un) }\end{array}$ & $\begin{array}{c}\text { Frequência } \\
\text { PSE/Período (\%) }\end{array}$ & $\begin{array}{c}\text { Frequência } \\
\text { relativa (\%) }\end{array}$ \\
Período 1 & PSE & 16 & 8,2 & 1,87 \\
& Normal & 179 & --- & 20,96 \\
Período 2 & PSE & 44 & 7,06 & 5,15 \\
& Normal & 579 & --- & 67,8 \\
Período 3 & PSE & 9 & 25 & 1,05 \\
Total & Normal & 27 & --- & 3,16 \\
PSE & & 854 & & 100 \\
\hline
\end{tabular}

As frequências absolutas e relativas apontam que o Período 2 de transporte apresentou maior quantidade de carcaças com PSE; entretanto; quando se observa a frequência por período de transporte, ou seja, a incidência de carne PSE por cada amostra de transporte, o Período 2 seria o mais econômico, pois apresentou $7,06 \%$ de carne PSE enquanto o Período 1 apresentou $8,2 \%$ e o Período 3 superou os $20 \%$.

Este resultado pode estar relacionado ao estresse inicial do animal devido às operações de movimentação e carregamento, condições do manejo e do veículo e, em curto tempo de viagem da granja ao abatedouro, considerando que o animal ainda não tenha se recuperado. Em seu estudo, Ochove et al. (2010) constataram que a curta distância entre a granja e o abatedouro ocasionou maior nível de estresse agudo representado pelo porcentual de animais cansados e que as distâncias médias e longas foram responsáveis pelo estresse crônico nos animais, representado por maior número de mortalidade. De acordo com a EMBRAPA (2012) no transporte acima de três horas o animal inicia um estágio de estresse avançado.

Os três períodos de transporte apresentaram dados semelhantes com médias similares à média total. $\mathrm{O} \mathrm{pH}_{45}$ e a temperatura de carcaça (TC) indicaram pequena variação das médias, combinadas com baixos valores de CV\% demonstrando uma precisão amostral; entretanto, para o tempo de embarque (TE), distância (DK), velocidade média (VM) e tempo de descanso (TD), os coeficientes de variação (CV\%) apresentaram menor precisão amostral implicando em grande variação entre os dados para os Períodos 1 e 2 sinalizando maior dispersão nos dados dessas variáveis.

A variável ITU, por se tratar de único valor referente à data de avaliação, não possui variação amostral. Para o cálculo de verificação foi utilizada a Eq. 1, de Roller \& Goldman (1969) e as temperaturas ambientes relacionadas ao conforto térmico para suínos em terminação, entre temperatura de 12 a $18{ }^{\circ} \mathrm{C}$ e umidade relativa do ar de $70 \%$ (Leal \& Nääs, 1992). Constatou-se, desta forma, que o valor de 70,03 do ITU calculado se encontra acima da faixa de conforto térmico entre 59 e 65; contudo, o valor do ITU pode ser 
aceitável como zona de conforto visto que não se encontra na faixa de ITU crítico para o suíno em terminação (38 e 80).

Observando a Tabela 2 constata-se que a variável temperatura de carcaça (TC) possui baixos valores negativos $(\mathrm{p}<0,01)$ na influência do $\mathrm{pH}_{45}$ para todos os períodos de transporte sugerindo que, se ocorrer o aumento da temperatura da carcaça, reduzirá o $\mathrm{pH}_{45}$ da carne e vice-versa. O Período 3 apresentou correção média $(-0,5385)$, o que pode ser explicado em virtude do mesmo expor o animal a um tempo maior de estresse em consequência do tempo de viagem ser superior a 1,67 h e também por ser a distância entre a granja ao frigorífico, de $90 \mathrm{~km}$. Segundo Dalla-Costa et al. (2010), suínos submetidos a transporte de curta duração (distância em torno de $80 \mathrm{~km}$, com duração inferior a três horas) apresentam mais sintomas de estresse, o que influencia a qualidade da carne, mais do que os animais submetidos a viagens de média e longa distância, em razão do ritmo de adaptação dos suínos às situações de estresse.

Observam-se correlações positivas e significativas entre o $\mathrm{pH}_{45}$ e o tempo de viagem (TV) e tempo de embarque (TE), nos períodos de transportes 1 e 2 , respectivamente, indicando que o aumento do tempo de embarque implicará no aumento do $\mathrm{pH}_{45}$, considerando-se o manejo adequado dos animais, fato que também se justifica pela correlação negativa e significativa entre a TC e o TE cujo aumento do TE reduz o TC, visto que carcaças com menor temperatura apresentam melhor rendimento e melhor $\mathrm{pH}_{45}$.

A temperatura de carcaça (TC) obteve correlação positiva e significativa com tempo de descanso médio (TD) inferindo que o aumento do tempo de descanso médio nas baias aumenta a temperatura de carcaça (TC). Em alguns países da Europa a aplicação de manejo pré-abate e o transporte adequado influenciam positivamente na qualidade da carne não sendo necessária a utilização do tempo de descanso no frigorífico porém, embora seja possível alcançar, na Europa, níveis satisfatórios, as baias dos frigoríficos representam, de modo geral, um ambiente novo ao animal, além de outros fatores como o barulho agudo decorrente de maquinários e equipamentos em funcionamento, que estressam os animais, tal como a mistura de lotes representando um ambiente hostil aos animais. Em relação às demais variáveis, não houve correlações significativas com a TC.

O tempo de embarque (TE) apresentou correlações negativas $(\mathrm{p}<0,01)$ com as variáveis tempo de transporte (TV), distância entre a granja e o frigorífico (DK), velocidade média (VM) e tempo de descanso médio (TD) sugerindo que o manejo e a movimentação adequada no embarque dos animais implicam em melhorar o comportamento dos tratadores e o aumento do tempo de embarque possibilitando a redução das demais variáveis. Segundo Silveira (2010), no embarque dos suínos o estresse causado por diversos fatores pode aumentar o batimento cardíaco variando de 80 até 250 batimentos por minuto, para o que seria necessário maior tempo entre o embarque e o abate do animal, permitindo-lhe recuperação do estresse inicial.

Nota-se que o tempo de transporte (TV) teve significativa ( $p$ $<0,01)$ correlação com a velocidade média sendo inversamente proporcional, o que se previa pois o aumento de uma implica na redução da outra; o mesmo ocorre com o TV e a DK haja vista que a correlação positiva indica que ambas estão direcionadas para o mesmo sentido.

Com relação à variável tempo de transporte, Bench (2007) classifica curta a duração da viagem de animais (0:15 min a 11 h e $59 \mathrm{~min}$ ) e longa (acima de $12 \mathrm{~h}$ ). Com base neste conceito, o estudo considerou apenas viagens de curta duração $(2,33$ a $0,28 \mathrm{~h})$.

A partir da Tabela 3 observa-se a incidência de carne PSE em razão do tempo de viagem (TV) e o tempo de descanso médio

Tabela 2. Coeficientes de correlação de Spearman entre as variáveis analisadas para os três períodos de transporte

\begin{tabular}{|c|c|c|c|c|c|c|c|c|}
\hline $\begin{array}{l}\text { Período de } \\
\text { transporte }\end{array}$ & Variáveis & TC & ITU & TE & TV & DK & VM & TD \\
\hline 1 & $\mathrm{pH}_{45}$ & $-0,228 * \star$ & --- & $-0,0209^{n s}$ & $0,1473^{*}$ & $-0,0653^{\text {ns }}$ & $-0,0699^{n s}$ & $-0,0803^{\text {ns }}$ \\
\hline 2 & & $-0,340^{\star *}$ & -- & $0,2893^{* *}$ & $-0,0153^{\text {ns }}$ & $-0,0420^{\text {ns }}$ & $-0,0496^{\mathrm{ns}}$ & $-0,0529^{\text {ns }}$ \\
\hline 3 & & $-0,538 * *$ & --- & -- & -- & -- & -- & -- \\
\hline 1 & TC & & --- & $-0,1397^{*}$ & $0,1293^{\text {ns }}$ & $0,0657^{\text {ns }}$ & $0,0233^{\text {ns }}$ & $0,2445^{* *}$ \\
\hline 2 & & & --- & $-0,0733^{n s}$ & $-0,0470^{\mathrm{ns}}$ & $-0,0412^{\mathrm{ns}}$ & $-0.0724^{\mathrm{ns}}$ & $-0.0385^{\mathrm{ns}}$ \\
\hline 3 & & & --- & -- & --- & --- & --- & -- \\
\hline 1 & ITU & & & --- & --- & --- & --- & --- \\
\hline 2 & & & & --- & --- & --- & --- & --- \\
\hline 3 & & & & --- & --- & --- & --- & --- \\
\hline 1 & $\mathrm{TE}$ & & & & $-0,2473^{* *}$ & $-0,1564^{*}$ & $-0,2920 * *$ & $-0,2592^{* *}$ \\
\hline 2 & & & & & $-0,2684^{\star *}$ & $-0,4350 * *$ & $-0,4290$ ** & $-0,4324$ ** \\
\hline 3 & & & & & --- & --- & --- & --- \\
\hline 1 & TV & & & & & $-0,0248^{\text {ns }}$ & $-0,1820 * *$ & $0,2337^{* *}$ \\
\hline 2 & & & & & & 0,8974 ** & $0,7907^{* *}$ & $0,6945^{\star *}$ \\
\hline 3 & & & & & & --- & --- & --- \\
\hline 1 & DK & & & & & & $0,9571 * *$ & $0,7512^{* *}$ \\
\hline 2 & & & & & & & $0,9575^{\star \star}$ & 0,8532 ** \\
\hline 3 & & & & & & & --- & --- \\
\hline 1 & VM & & & & & & & $0,6040 * *$ \\
\hline 2 & & & & & & & & $0,9083^{\star *}$ \\
\hline 3 & & & & & & & & --- \\
\hline
\end{tabular}

${ }^{\star \star} \mathrm{p}<0,01 ;{ }^{\star} \mathrm{p}<0,05 ; \mathrm{ns} \mathrm{p}>0,05 ; \mathrm{pH}_{45}$. Potencial hidrogeniônico após 45 min do abate; TC - Temperatura de carcaça, em ${ }^{\circ} \mathrm{C}$; ITU - Índice de temperatura e umidade; TE - Tempo de embarque, h; TV - Tempo de viagem, h; DK - Distância entre a granja até 0 abatedouro, km; VM - Velocidade média do veículo durante 0 transporte, $\mathrm{km}^{-1}{ }^{-1}$; TD - Tempo de descanso médio, $\mathrm{h}$ 
(TD), em que do total de carcaça que apresentou carne PSE para o período 1 de transporte, $62,5 \%$ incidiram no intervalo de descanso superior a $10,1 \mathrm{~h}$; já para o período 2 a maior incidência de carne PSE foi no intervalo de descanso do animal entre $5,1 \mathrm{a} 10 \mathrm{~h}$, com $77,3 \%$ enquanto no período $3,100 \% \mathrm{da}$ ocorrência de carne PSE foi no intervalo de descanso entre $0 \mathrm{a}$ $5 \mathrm{~h}$. Em termos globais o período 2 de transporte foi, para os dados analisados, o mais econômico e o tempo de descanso médio entre 0 a $5 \mathrm{~h}$ é mais recomendando.

Tabela 3. Incidência de carne PSE em razão do tempo de viagem e tempo de descanso (em \%)

\begin{tabular}{|c|c|c|c|c|}
\hline \multirow{2}{*}{$\begin{array}{c}\text { Tempo de viagem } \\
\text { (TV, h) }\end{array}$} & \multicolumn{3}{|c|}{ Tempo de descanso médio (TD, h) } & \multirow{2}{*}{ Total (TV)* } \\
\hline & 0 a 5 & 5,1 a 10 & $>10,1$ & \\
\hline $1=0$ a 0,83 & 18,8 & 18,8 & 62,5 & $8,21^{(\mathrm{a})}$ \\
\hline $2=0,84 \mathrm{a} 1,66$ & 4,5 & 77,3 & 18,2 & $7,06^{(b)}$ \\
\hline $3=>1,67$ & 100,0 & 0,00 & 0,00 & $25,0^{\text {(c) }}$ \\
\hline Total (TD)* & $1,63^{(d)}$ & $4,33^{(\mathrm{e})}$ & $2,10^{(f)}$ & \\
\hline
\end{tabular}

*854 carcaças: Análise 1 - Tempo de viagem ${ }^{(a)} 195$ carcaças; ${ }^{(b)} 623$ carcaças; () 36 carcaças; Análise 2 - Tempo de descanso médio ${ }^{(d)} 14$ carcaças; ( ${ }^{(e)} 37$ carcaças; ${ }^{(t)} 18$ carcaças

A partir da regressão logística múltipla foram testados e simulados modelos probabilísticos e realizado o teste de qualidade de ajuste de Hosmer \& Lemeshow indicando a possibilidade de realização da regressão logística. $\mathrm{O}$ modelo escolhido neste estudo apresentou maior força de predição.

O modelo reduzido obtido apresentou menor valor de AIC com melhor ajuste dos dados gerados pelo processo stepwise utilizando o critério da razão de verossimilhança como exclusão da variável do modelo e o teste Wald como análise de cada parâmetro do modelo final, ambos com nível de significância de 0,1 , em que se consideraram significativas para qualidade da carne suína, quatro variáveis: temperatura da carcaça (TC), tempo de embarque (TE), velocidade média do veículo durante o transporte (VM) e tempo de descanso médio (TD) conforme Tabela 4.

Tabela 4. Modelo de regressão logística

\begin{tabular}{crcrr}
\hline Variável & \multicolumn{1}{c}{ B } & Erro padrão & \multicolumn{1}{c}{$\mathbf{X}^{\mathbf{2}}$} & $\operatorname{Pr}\left(\mathbf{X}^{2}\right)$ \\
TC & $-0,4874$ & 0,1361 & 12,8300 & 0,0003 \\
TE & 0,4531 & 0,2496 & 3.2957 & 0,0695 \\
VM & $-0,0316$ & 0,0151 & 4,3720 & 0,0365 \\
TD & 0,2210 & 0,0677 & 10,6557 & 0,0011 \\
Constante & 20,5824 & 5,4936 & 14,0373 & 0,0002 \\
\hline
\end{tabular}

Desvio residual $=454,47 ; \mathrm{AIC}=481,45$

No modelo a probabilidade de uma carcaça apresentar incidência de carne PSE, é estimada pela relação (Eq. 4):

$\mathrm{PSE}=\frac{\exp (20,5824-0,4874 \mathrm{tc}+0,4531 \mathrm{te}-0,0316 \mathrm{vm}+0,2210 \mathrm{td})}{1+\exp (20,5824-0,4874 \mathrm{tc}+0,4531 \mathrm{te}-0,0316 \mathrm{vm}+0,2210 \mathrm{td})}$

Neste modelo as variáveis que apresentaram significância, consideradas ótimas ( $\mathrm{p}<0,001)$, foram: TC, TD e a constante; a variável VM apresentou significância $(\mathrm{p}<0,05)$ e TE significância $(\mathrm{p}<0,10)$. A porcentagem global de classificação do modelo foi de $91,8 \%$, indicando que o modelo é satisfatório para predições futuras de incidência de carne PSE para suínos. Assim se considera, com este desempenho, o modelo bem ajustado.
As razões de chances, odds ratio (OR), para as variáveis explicativas foram 0,614 para temperatura de carcaça; 1,573 para tempo de embarque; 0,969 para velocidade média e 1,247 para tempo de descanso médio. Desta forma, com relação ao odds ratio se destacam as variáveis TE e TD indicando que não apenas as operações de embarque devem ser realizadas cuidadosamente mas também o manejo, que deve ser adequado, desde que, com base nas demais constantes, o tempo de embarque menor que uma hora apresenta 1,573 mais chances de incidência de carne PSE que o tempo superior a este valor, representando um risco de aproximadamente $57,3 \%$. Da mesma forma, o tempo de descanso na baia superior a seis horas mostrou 1,247 mais chance de apresentar carne PSE do que valores inferiores, ou seja, risco de $24,7 \%$. TE maior que uma hora e TD menor que seis horas aumentam a possibilidade de se obter a carne suína dentro da faixa de $\mathrm{pH}_{45}$ considerada normal, isto é, com melhor qualidade. Este resultado é contrário às recomendações da Portaria $\mathrm{n}^{\circ} 711$, de 1995, do Ministério da Agricultura, do Abastecimento e da Reforma Agrária, que regulamenta um tempo de descanso mínino de 8 h e máximo de 24 h para suínos, antes do abate; este tempo de descanso poderá ser prolongado para animais transportados a longas distâncias ou feita viagem acidentada sendo os animais devidamente alimentados e posteriormente observado o período mínimo de descanso recomendado pela norma.

No experimento realizado por Smiecinska et al. (2011) com 44 suínos separados em dois grupos, dentre os quais 20 suínos foram abatidos imediatamente após o transporte e 24 foram abatidos após o tempo de descanso de $24 \mathrm{~h}$, apresentando resultados similares para ocorrência de carne PSE nos dois grupos; os suínos abatidos imediatamente apresentaram maior rendimento da carcaça e $\mathrm{pH}$ melhor do que os suínos submetidos ao tempo de descanso sinalizando que o manejo pré-abate e as condições de transporte adequadas não afetam a qualidade da carne.

Assim, o tempo de descanso só é recomendado quando o estresse é induzido pelo manejo pré-abate inadequado; a partir de então, suínos manejados de acordo com as recomendações de bem-estar animal não necessitam do tempo de descanso podendo ser abatidos imediatamente após o transporte.

Também se observou, neste experimento, que a temperatura de carcaça acima de $38^{\circ} \mathrm{C}$ apresentou maior incidência de carne PSE do que as carcaças com temperatura inferior a este valor (Figura 1). Assim, a probabilidade (38,6\%) de carne normal tende a aumentar quando a temperatura de carcaça diminui.

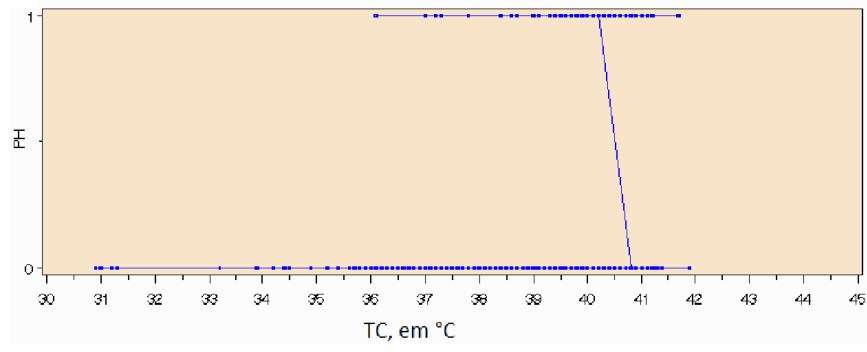

Figura 1. Concentração de carne PSE em relação à temperatura de carcaça (TC) 
A velocidade média durante o transporte $\left(<50 \mathrm{~km} \mathrm{~h}^{-1}\right)$ mostrou-se com poder de influência na incidência de carne PSE do que velocidade superior a este valor. Desta forma, pode-se inferir que a probabilidade $(3,1 \%)$ de carne PSE tende a reduzir quando a velocidade média se mantém na faixa de $50 \mathrm{a} 60 \mathrm{~km} \mathrm{~h}^{-1}$. As novas condições durante o transporte para os suínos, como vibrações, mudanças súbitas na velocidade do caminhão, variação de temperatura ambiental e densidade, podem provocar medo e estimular o estresse (Dalla-Costa et al., 2010).

Sugere-se, para futuros estudos incorporar, ao modelo, outras variáveis relacionadas ao manejo pré-abate, ambiência e qualidade da carne, tornando-o mais robusto.

\section{Conclusões}

1. A regressão logística múltipla foi adequada para a construção de um modelo, por meio da seleção de variáveis stepwise, de vez que reduziu para quatro o número de sete variáveis explicativas. O modelo pode ser considerado confiável devido à alta probabilidade de predição de $91,8 \%$.

2. As variáveis temperatura da carcaça, tempo de embarque, velocidade média do veículo e tempo de descanso médio exercem relação direta sobre a incidência de carne PSE.

3. O modelo sugere adequação da logística de transporte dos animais com o período de descanso: maior tempo de embarque e menor tempo de descanso nas baias.

\section{Literatura Citada}

Baêta, F. C.; Souza, C. F. Ambiência em edificações rurais: Conforto animal. 2ed. Viçosa: UFV, 2010. 269p.

Bench, C. Welfare implications of pig transport journey duration. Scientific background of current international standards. Ontario: Agriculture and Agri-Food Canada, 2007.25p.

BRASIL. Ministério da Agricultura, do Abastecimento e da Reforma Agrária. Portaria ${ }^{\circ}$ 711, de 1 de novembro de 1995. Disponível em: http://www.agricultura.gov.br. 21 Jul. 2014.

Costa, N. L.; Fiego, D. P.; Dall'Olio, S.; Davoli, R.; Russo, V. Combined effects of pre-slaughter treatments and lairage time on carcass and meat quality in pigs of different halothane genotype. Meat Science, v.61, p.41-47, 2002.

Dalla-Costa , O. A.; Faucitano, L.; Coldebella, A.; Ludke, J. V.; Peloso, J. V.; Dalla-Roza, D.; Paranhos da Costa, M. J. R. Effects of the season of the year, truck type and location on truck on skin bruises and meat quality in pigs. Livestock Science, v.107, p.29-36, 2007.

Dalla-Costa , O. A; Ludke, J. V.; Costa, M. J. R. P.; Faucitano, L.; Peloso, J. V.; Dalla-Roza, D. Efeito das condições pré-abate sobre a qualidade da carne de suínos pesados. Archivos de Zootecnia, v.59, p.391-402, 2010.

Delezie, E.; Swennen, Q.; Buyse, J.; Decuypere, E. The effect of feed withdrawal and crating density in transit on metabolism and meat quality of broilers at slaughter weight. Poultry Science Association, v.86, p.1414-1423, 2007.
EMBRAPA - Empresa Brasileira de Pesquisa Agropecuária. Sistemas de produção de suínos. http://sistemasdeproducao. cnptia.embrapa.br/FontesHTML/Suinos/SPSuinos/index. html. 12 Abr. 2012

Giespert, M.; Faucitano, L.; Oliver, M. A.; Guàrdia, M. D.; Coll, C.; Siggens, K.; Harvey, K.; Diestre, A. A survey of preslaughter conditions, halothane gene frequency, and carcass and meat quality in five Spanish pig commercial abattoirs. Meat Science, v.55, p.97-106, 2000.

Hosmer, D. W.; Lemeshow, S.; Sturdivant, R. Applied logistic regression. 3.ed. Hoboken: John Wiley \& Sons, 2013. 528p.

Leal, P. M.; Nääs, I. A. Ambiência animal. In: Cortez, L. A. B.; Magalhães, P. S. G. (org.). Introdução à engenharia agrícola. Campinas: UNICAMP, 1992. p.121-135.

Ludtke, C. B.; Dalla-Costa, O. A.; Roça, R. O.; Silveira, E. T. F.; Athayde, N. B.; Aráujo, A. P; Mello Junior, A.; Azambuja, N. C. Bem-estar animal no manejo pré-abate e a influência na qualidade da carne suína e nos parâmetros fisiológicos do estresse. Ciência Rural, v.42, p.532-537, 2012.

Mendes, C. A. B.; Veja, F. A. C. Técnica de regressão logística aplicada à análise ambiental. Revista Geografia, v.20, p.530, 2011.

Mota-Rojas, D.; Becerril-Herrera, M.; Roldan-Santiago, P.; Alonso-Spilsbury, M.; Flores-Peinado, S.; RamírezNecoechea, R.; Ramírez-Telles, J. A.; Mora-Medina, P.; Pérez, M.; Molina, E.; Soní, E.; Trujillo-Ortega, M. E. Effects of long distance transportation and $\mathrm{CO}_{2}$ stunning on critical blood values in pigs. Meat Science, v.90, p.893-898, 2012.

Ochove, V. C. C.; Caramori Júnior, J. G.; Corrêa, G. S. S.; Bertoloni, W.; Roça, R. O.; Silva, G. S.; Cruz, R. A.S. Influência da distância no bem-estar e qualidade de carne de suínos transportados em Mato Grosso. Revista Brasileira de Saúde e Produção Animal, v.11, p.1117-1126, 2010.

Ritter, M. J.; Ellis, M.; Berry, N. L.; Curtis, S. E.; Anil, L.; Berg, E.; Benjamin, M.; Butler, D.; Dewey, C.; Driessen, B.; DuBois, P.; Hill, J. D.; Marchant-Forde, J. N.; Matzat, P.; McGlone, J.; Mormede, P.; Moyer, T.; Pfalzgraf, K.; Salak-Johnson, J.; Siemens, M.; Sterle, J.; Stull, C.; Whiting, T.; Wolter, B.; Niekamp, S. R.; Johnson, A. K. Transport losses in market weight pigs: I. A review of definitions, incidence, and economic impact. The Professional Animal Scientist, v.25, p.404-414, 2009.

Roller, W. L.; Goldman, R. F. Response of swine to acute heat exposure. Transactions of the American Society of Agricultural Engineers, v.12, p.164-169, 1969.

Roriz, M. Psicrom 1.0 - Relações psicométricas. São Carlos: Universidade Federal de São Carlos, 2003.

Santos, R. C.; Reis, J. G. M.; Machado, S. T.; Jordan, R. A.; Oliveira, R. V.; Moura, G. B. Perdas econômicas decorrentes do transporte de suínos em Mato Grosso do Sul: Estudo de caso. Enciclopédia Biosfera, Centro Científico Conhecer, v.9, p. 1682-1697, 2013.

Sampaio, C. A. P.; Cristiani, J.; Dubiela, J. A.; Boff, C. E.; Oliveira, M. A. Avaliação do ambiente térmico em instalação para crescimento e terminação de suínos utilizando os índices de conforto térmico nas condições tropicais. Ciência Rural, v.34, p.785-790, 2004. 
Santiago, J. C.; Caldara, F. R.; Santos, V. M. O.; Seno, L. O.; Garcia. R. G.; Almeida Paz, I. C. L. Incidência da carne PSE (pale, soft, exsudative) em suínos em razão do tempo de descanso pré-abate e sexo. Arquivo Brasileiro de Medicina Veterinária e Zootecnia, v.64, p.1739-1746, 2012.

Saraiva, E. P.; Oliveira, R. F. M.; Donzele, J. L.; Ferreira, A. S.; Ferreira, R. A.; Rezende, W. O.; Orlando, U. A. D.; Vaz, R. G. M. V. Níveis de Proteína Bruta em Rações para Suínos Machos Castrados em Fase Inicial de Crescimento, mantidos em Ambiente de baixa temperatura. Revista Brasileira de Zootecnia, v.32, p.1690-1696, 2003.

Schwartzkopf-Genswein, K. S.; Faucitano, L.; Dadgar, S.; Shand, P.; González, L. A.; Crowe, T. G. Road transport of cattle, swine and poultry in North America and its impact on animal welfare, carcass and meat quality: A review. Meat Science, v.92, p. 227-243, 2012.
Shtatland, E. S.; Kleinman, K.; Cain, E. M. Stepwise methods in using SAS proc logistic ans SAS enterpise miner for prediction. Harvard Medical School, 2003. Paper 258-28.

Silveira, E .T. F. Manejo pré-abate de suínos e seus efeitos na qualidade da carcaças e carne. Suínos \& Cia, Ano VI, p.2433, 2010.

Smiecinska, K.; Denaburski, J.; Sobotka, W. Slaughter value, meat quality, creative kinase activity and cortisol levels in the blood serum of growing-finishing pigs slaughtered inmediately after transport and after a rest period. Polish Journal of Veterinary Sciences, v.14, p.47-54, 2011.

Venturini, K. S.; Sarcinelli, M. F.; Silva, L. C. Abate de suínos., Espiríto Santo: UFES, 2007.7p, Boletim Técnico PIE-UFES: 01407. 